\title{
Correction to: Severe hospital-acquired hyponatremia in acutely ill children receiving moderately hypotonic fluids
}

\author{
Saara Lehtiranta ${ }^{1,2}(\mathbb{0}) \cdot$ Minna Honkila ${ }^{1,2}\left(\right.$ Merja Kallio $^{2,3} \cdot$ Kimmo Halt $^{1,2} \cdot$ Niko Paalanne $^{1,2} \cdot$ Tytti Pokka $^{1,2}$. \\ Terhi Tapiainen ${ }^{1,2,4}$ (1)
}

Published online: 21 September 2021

(c) IPNA 2021

\section{Correction to: Pediatr Nephrol}

https://doi.org/10.1007/s00467-021-05227-0

Due to an unfortunate error during the processing of this article, Figure 1 was published with an erroneous legend. The original figure legend should be "Fig. 1 Study profile". The original article has been corrected.

Publisher's note Springer Nature remains neutral with regard to jurisdictional claims in published maps and institutional affiliations.

The original article can be found online at https://doi.org/10.1007/ s00467-021-05227-0.

Saara Lehtiranta saara.lehtiranta@student.oulu.fi

1 Department of Pediatrics and Adolescent Medicine, Oulu University Hospital, PO Box 23, N90029 OYS Oulu, Finland

2 PEDEGO (Pediatrics, Dermatology, Gynecology and Obstetrics) Research Unit and Medical Research Centre Oulu, University of Oulu, Oulu, Finland

3 Department of Pediatric Cardiology, New Children's Hospital, University Hospital of Helsinki, Helsinki, Finland

4 Biocenter Oulu, University of Oulu, Oulu, Finland 